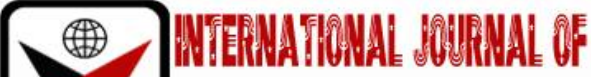

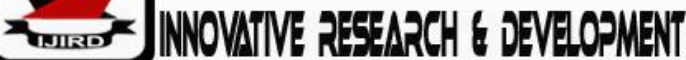

ISSN 2278 - 0211 (Online)

\section{Hypothetical Application of C-Matrix via GIS in Road Network Analysis of Oriire Local Government Area, Oyo State, Nigeria}

\begin{tabular}{c} 
Babalola Obasanjo James \\
\hline Ph.D. Student, Department of Transport Management, \\
Ladoke Akintoka University of Technology, Ogbomoso, Nigeria \\
Ogundele Ayodele Victor \\
Ph.D. Student, Department of Transport Management, \\
Ladoke Akintoka University of Technology, Ogbomoso, Nigeria \\
Remi Aworemi \\
Professor, Department of Transport Management \\
Ladoke Akintoka University of Technology, Ogbomoso, Nigeria \\
Dr. Christopher A. Wojuade \\
Senior Lecturer, Department of Transport Management, \\
Ladoke Akintoka University of Technology, Ogbomoso, Nigeria \\
Dr. B.B. Ayantoyinbo \\
Senior Lecturer, Department of Transport Management, \\
Ladoke Akintoka University of Technology, Ogbomoso, Nigeria \\
Solomon Onilede \\
Ph.D. Student, Department of Pure \& Applied Physics, \\
Ladoke Akintoka University of Technology, Ogbomoso, Nigeria
\end{tabular}

Abstract:

Given the crucial of geographical information system (GIS) in road network analysis and management within the society, this study offer hypothesis on the use of simple matrix to evaluation road network connectivity. The was carried out in Oriire local government area of Oyo state with the total area of about 2,116km2 and 206, 782 projected human populations. Multistage sampling was adopted to select seven (7) villages including the agricultural market (Tewure). Secondary method of data collection was used which incorporates, data acquisition, scanning and remote sensing. It was found out that maximum of these villages are connected with minimal of three (3) routes with Onigba connected via 5 (five) routes that's the most connected village unluckily, Onigba was not made the principal marketplace. Although the GIS result shows their connectivity however it was also revealed that maximum of the routes have seasonal accessibility. It was concluded that, the local government therefore ought to come to their aids.

Keywords: Transportation, GIS, road network, C-Matrix

\section{Introduction}

Historically, transport networks are studied from a graph theory attitude, which is a branch of arithmetic offering standards and measures about the topology of networks taken into consideration as sets of nodes (vertices) related with the aid of hyperlinks (edges) (cesar \& igor, 2009). Accessibility is the ease with which activities at one location may be reached from some other through a selected travel model (suxia and xuan, 2003). Road networks are becoming a critical degree of evaluation for understanding how transportation pattern is distributed in the geographical spaces. Environmental issues, which include sustainable transportation, have interaction with range of stakeholders along with authorities' entities, nonprofits, communities (rural) and enterprise groups. The complex nature of conducting sustainable transportation is without problems beyond the scope of any unmarried company's political jurisdiction or technical ability (watts \& witham, 2012). Network is largely used for the spatial pattern of transport facilities in a given region. A regional transport device is the combinations of point to point mobility are the basic of all types of flows and are liable for spatial arrangements (saxsema, 2013). The usage of GIS era in development of urbanization, the sensible delivery machine and management can provide a very strong answer. Statistics associated with transportation network is used inside the green planning, designing, construction, upkeep and management of the transport system. 


\section{Literature Review}

Transport network is evaluated to achieve a positive transport network and decide particular factors through it. This analysis keep in mind the go with the flow of automobiles within the network created, the engineering of the network itself and the available modes of transportation. The facts accrued from the evaluation of road networks are used for incorporating modifications into the network as well as improve of standard transportation network. The transport network evaluation is needed to be carried out by means of experts who will take heeds of various factors together with people, freight, sorts of vehicles, avenue connectivity amongst others. It is milked to decide the go with the flow of motors through a transport network shape, normally the use of mathematical image theory. It could integrate one mode of transport for instance strolling and automobile to multi-modal journeys. Network analysis permits you to clear up troubles, together with locating the most efficient travel direction, generating journey instructions, finding the nearest facility, defining service regions based on journey time. Network analysis is extensively used in the study of social networks, however to update pretty little within the spatial analysis of cities. Even as the observe of spatial networks is going lower back to Euler and his well-known puzzle of Konigsberg's seven bridges in the 18th century, there had been till recently no freely reachable gear to be had for metropolis designers and planners to calculate computation extensive spatial accessibility measures on dense networks of city streets and homes. Network evaluation remains one of the maximum giant and chronic research areas in geographic information science (GIS). This is accompanied by means of a concise but comprehensive evaluation of the contemporary skills for network analysis in GIS, and the resultant deficiencies in GIS implementations of networks. A fixed of demanding situations is recommended for network analysis in GIS, through extended implementation of present network theory, through enlargement of existing concept and practice inside the areas of network design and area, and through interactions with a wide kind of different disciplines

\subsection{Accessibility Graph-Theoretic Measures}

Graph-theoretic measures of nodal accessibility may be considered as an improvement in network analysis. Through measuring graph-theoretic connectivity we handiest can compare the degree of network structural changes, however we cannot perceive what in my opinion has changed at the network, and what causes these structural adjustments. To measure nodal accessibility and its impact on the network we need to deal with graph as a matrix. There are a set of graph-theoretic accessibility measures derived from a set of matrix, e. g. C matrix (offers you the direct connections among nodes), T matrix (gives you the direct and oblique connections among nodes), D matrix or Shimbel matrix (offers you the topologic shortest-distance between any pair of nodes) and L matrix (offers you the actual shortestdistance between any pair of nodes), but for this study we most effective going to refer those attributable to matrix D and L (extraordinarily critical while studying spatial networks), for planar graph empirical have a look at and matrix D, for nonplanar graph empirical have a look at respectively. Geographers and other spatial analysts frequently boost the difficulty of the effect of transport networks on spatial organization, however only few of them base their reviews on empirical studies and mathematical foundations. With nodal accessibility graph-concept measures, geographers try to see if the recording degree the impact of the proposed planar and non-planar graph networks on the accessibility of settlements as it changed into use in Portugal mainland and airport-cities in north-European continent.

\subsection{Geographical Information System}

GIS has been defined as, 'an included collection of computer software and data used to view and manage records about geographic places, analyze spatial relationships, and model spatial techniques. A GIS affords a framework for amassing associated statistics so that it may be displayed and analyzed. It gives us a sustainable framework and consumer output as software. A part of GIS workspace when incorporated can provide a very sturdy framework to transportation branch, strategies and analysis device. The device will deal with complicated road problem, make certain higher connectivity, shortest and quickest path among others. Roads are the ever-present network. Streets have two transition ramps. They shape a multilevel network at the same time as most roads are at surface degree, bridges, tunnels, and dual carriageway interchanges move each different in elevation, an easy overpass has two levels, and a dual carriageway interchange typically has four. With geographic information system (GIS) software program, you could examine a transportation network to aid making plans, goals which includes relieving congestion, mitigating pollution, optimizing transporting products, and forecasting demand for transportation. The road function is more vital in the maps, as it represents a first-rate map characteristic. There are many GIS software that offers a line characteristic generalization facility. The geometric operations are worried in this generalization like selection, merge, symbolization, elimination among others. But there's no proper definition for generalization. In ArcGIS 9.3, a point dispose of tool makes use of' Douglas-Peucker (DP) algorithm. These algorithms become most popular algorithm, which becomes useful in many applications like road, river, and coastal line generalization.

\section{Methodology}

This work was done in Oriire local government region of Oyo state, Nigeria. It is inhabited particularly by the Yoruba people. The economic system of Oriire neighborhood is primarily based mainly on agricultural and handcrafts. Agricultural merchandise encompass yams, corn, (maize) cassava (manvoc), beans, millet, plantains, tobacco, cocoa, palm oil, and palm kernel, kola nuts and fruits. Oyo state is located among the longitude of 3051.8 and 3058.9 east of green which meridian and the range of 7030. 3' and 7040. 2' north of the Equator. It's miles located on the South of Ogun State, North of kwara, and Western to the border and jap axis of Osun state. It coordinates are 70 19'60'n and 40 4' 0'E. Contemporary nearby time is 17:28; the sun rises at 09:01 and sets at 21:08 neighborhood time. The usual time zone for the observe area is UTC/GMT +1 . Oyo State covers approximately an area of 28,454 square kilometer and is ranked 14 th 
via size. The landscape consists of vintage tough rocks and dome formed hills, which upward push lightly from approximately 500 meters at the southern and attaining a height of approximately 1,219 meters above sea degree in the northern part. A few essential rivers that resource agriculture include Ogun, Oba, Oyan, Otin, Ofiki, Jala dam, Erinle and Osun River. The climate is equatorial, considerably with dry and moist season with fairly high humidity. The dry season lasts from November to March while the wet season begins from April and results in October. Average daily temperature stages between $250 c$ (77of) and 35oc (95. 0of), nearly throughout the year.

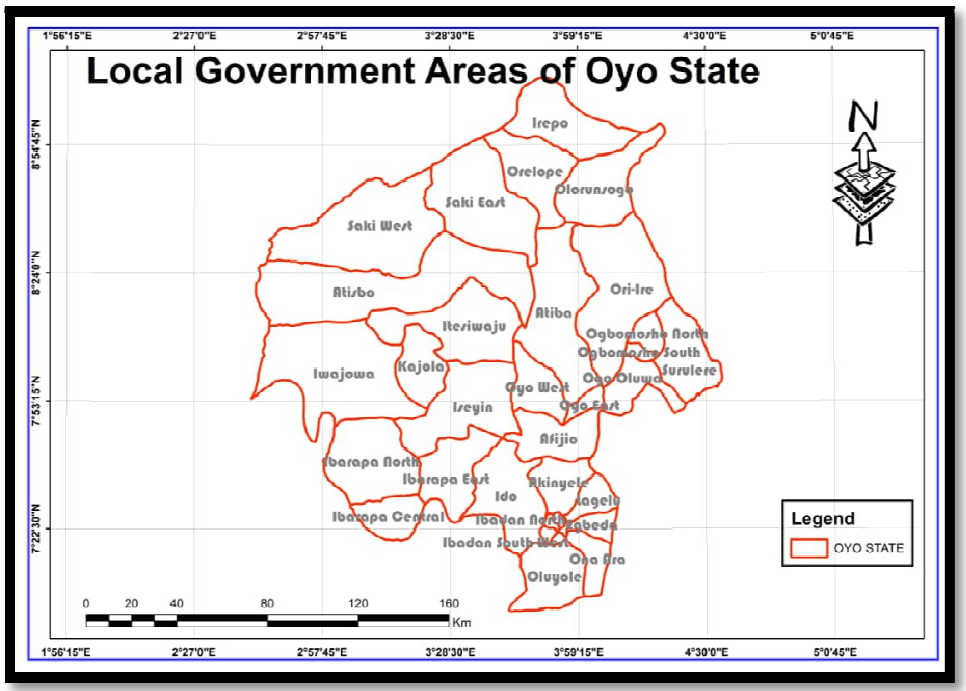

Figure 1: GIS Map of Oyo State Showing Local Government Areas Source: Author's Field Work, 2020

Oriire L. G. A., has an area of 2,116 km 2 making it the largest local government in Oyo state and a human populace of a hundred and fifty thousand, six hundred twenty eight(150,628), (census, 2006). A multistage sampling method was adopted to select local government with higher production in Oyo state. The first stage was the purposive choice of Orire local government area. The second stage was the random selection of the villages in percentage of the L. G. A village's population length. The targeted villages are Alaropo, Olokoto, Esinele, Yakoyo, Onigba and Ahorodada in Orire local government of Oyo North Senatorial District. Secondary methods of facts series have been used and it consists of: facts acquisition, scanning, georeferencing, digitization, spatial database query and analysis.

\section{Result Discussion}

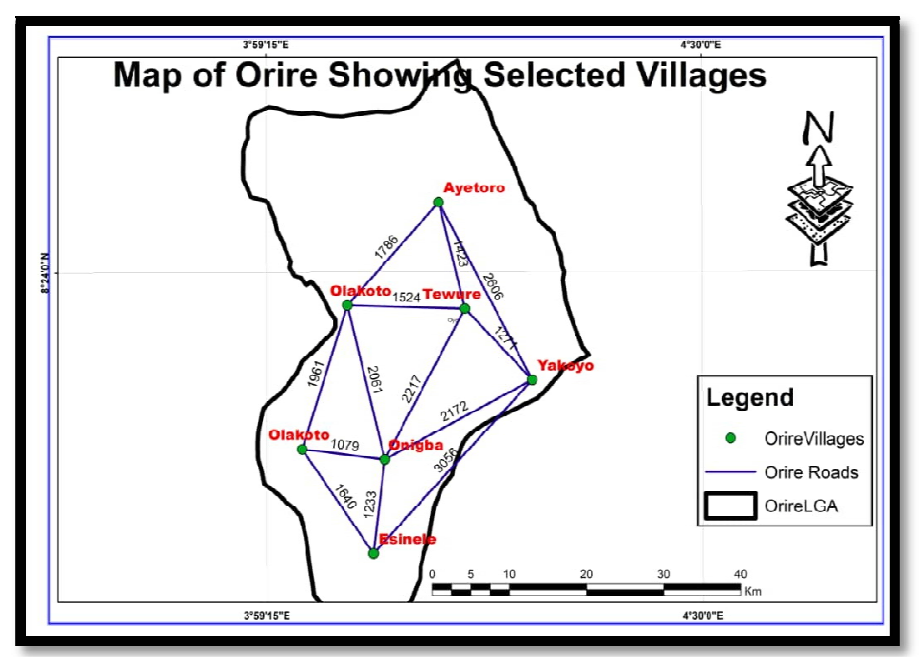

Figure 2: Coordinate Map of Oriire L.G.A. Showing Selected Villages Source: GIS Extract

\subsection{Model Specification}

To evaluate the level of connectivity of roads in the study area, the study employed simple connectivity matrix.

$$
C=\left\{\begin{array}{c}
a_{11} a_{12} a_{1 x} \\
a_{21} a_{22} a_{2 x} \\
a_{m 1} a_{m 1} a_{m x}
\end{array}\right\}
$$

Where all villages will be denoted by first two (2) alphabetsof their names (figure 1.2) 


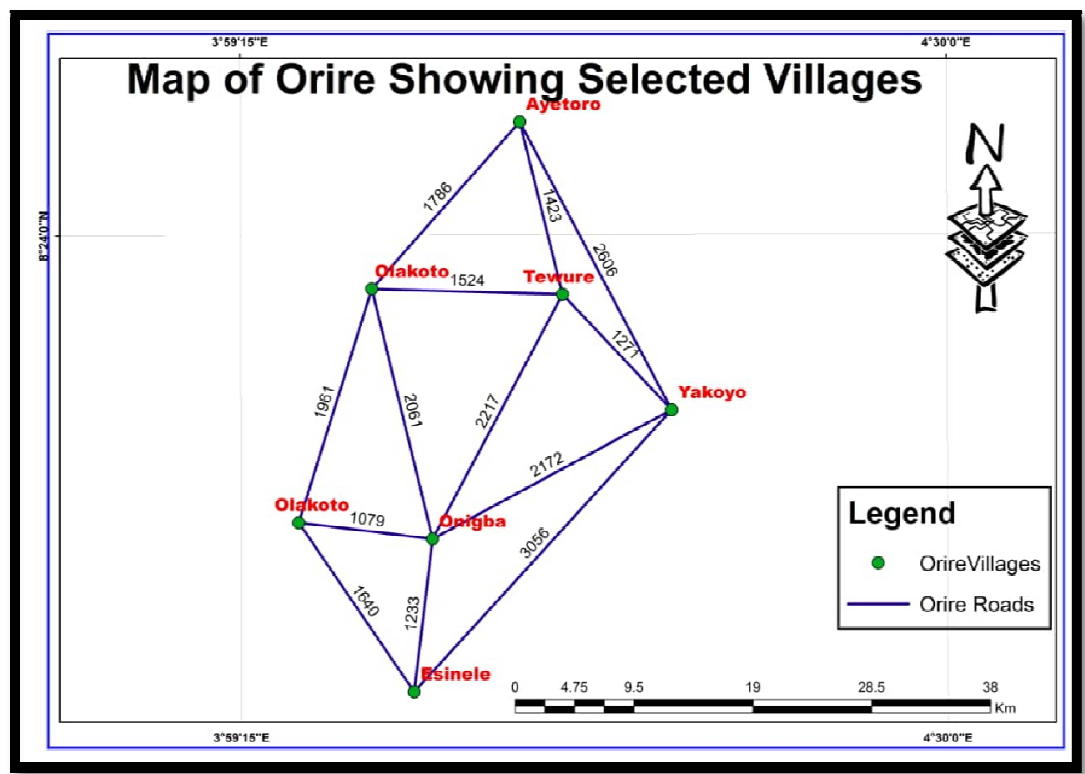

Figure 3: Coordinate Map of Selected Villages with Distance between Them Source: GIS Extract

\begin{tabular}{|c|c|c|c|c|c|c|c|}
\hline & AY & OL & ES & AH & ON & YA & TE \\
\hline AY & 0 & 1 & 0 & 0 & 0 & 1 & 1 \\
\hline OL & 1 & 0 & 0 & 1 & 1 & 0 & 1 \\
\hline ES & 0 & 0 & 0 & 1 & 1 & 1 & 0 \\
\hline AH & 0 & 1 & 1 & 0 & 1 & 0 & 0 \\
\hline ON & 0 & 1 & 1 & 1 & 0 & 1 & 1 \\
\hline YA & 1 & 0 & 1 & 0 & 1 & 0 & 1 \\
\hline TE & 1 & 1 & 0 & 0 & 1 & 1 & 0 \\
\hline
\end{tabular}

Table 1

$\boldsymbol{C}=\left(\begin{array}{ccccccc}0 & 1 & 0 & 0 & 0 & 1 & 1 \\ 1 & 0 & 0 & 1 & 1 & 0 & 1 \\ 0 & 0 & 0 & 1 & 1 & 1 & 0 \\ 0 & 1 & 1 & 0 & 1 & 0 & 0 \\ 0 & 1 & 1 & 1 & 0 & 1 & 1 \\ 1 & 0 & 1 & 0 & 1 & 0 & 1 \\ 1 & 1 & 0 & 0 & 1 & 1 & 0 \\ \Sigma & 3 & 4 & 33544 & & 3 \\ & & & \\ & & & \\ & & \end{array}\right.$

Where each cell representing a connection between two nodes gets a value of 1 (for instance, Ayetoro - Olotoko). Each cell that does not represent a direct connection gets a value of 0 (Yakoyo - Olokoto). Summation of row or column gives the degree of a node. From the network, Onigba is obviously the most connected since it has the highest summation of five (5) connectivity comparatively to all others with four (4) nodal accessibility (Olokoto, Yakoyo, and Tewure). Ayetoro, Esinele and Ahorodada had three (3) nodal connectivity. Though Onigba is the most connected node of the network however, all of the routes are at their terrible states. Virtually all the connecting routes are bad, therefore, repairs are suggested as maintenance action Table 2 below which revealed the conditions of routes in the network area and recommendations were made appropriately. 


\begin{tabular}{|c|c|c|c|c|}
\hline Rating & State of route & Description (road conditions) & Maintenance action & $\begin{array}{c}\text { Distance } \\
\text { (KM) }\end{array}$ \\
\hline Ayetoro-Yakoyo & Fair & $\begin{array}{c}\text { Alligator cracks, potholes, } \\
\text { slippage cracks }\end{array}$ & Major repair & 2006 \\
\hline Ayetoro-Tewure & Fair & Alligator cracks, potholes & Minor repairs & 1423 \\
\hline Ayetoro-Olokoto & Failed & Alligator cracks, potholes & Major repairs & 1524 \\
\hline Olokoto-Tewure & Poor & Slippage cracks, potholes & Total resurfacing & 1524 \\
\hline Olokoto-Onigba & Failed & Sliggage cracks, potholes & Major repairs & 2061 \\
\hline Tewure-Onigba & Failed & Un-tarred, rugged potholes & Major repairs & 2217 \\
\hline Tewure-Yakoyo & Poor & Un-tarred & Resurfacing & 1274 \\
\hline Yakoyo-Onigba & Poor & Sliggage cracks, potholes & Major repairs & 2172 \\
\hline Yakoyo-Esinele & Failed & Rugged and untarred & Total resurfacing & 3056 \\
\hline Onigba-Esinele & Failed & Cracks roughly paved & Total resurfacing & 1233 \\
\hline
\end{tabular}

Table 2: Rating Criteria (RC) and Thresholds of Routes Adapted from Ogwuche, Et Al 2013.

Source: GIS Captured 2020.

\section{Conclusion \& Recommendation}

Oyo state is predominantly dependent on road transport. The road network is being developed and maintained by the local, state and federal governments. The study area is characterized with a rural commercial centre which is Tewure, unfortunately the study revealed that, from the existing road network, Tewure is not the most connected. It was shown that Onigba is best connected to road network and the centrality of the study area therefore, Onigba can be best described as the village in between others.

It is difficult to recommend relocation of the commercial centre to Onigba however, Onigba can serve as a precommercial hub for the market days of Tewure. It is also pertinent for the local government to see road construction, rehabilitation and maintenance as a duty to promote rural efficiencies.

\section{References}

i. Adebayo Oluwasegun. H., (2015). A GIS-Based Model for Road Maintenance in Nigeria: A Case Study of Ikeja Road Network, Lagos, Nigeria. Department of Geography \& Regional Planning, Olabisi Onabanjo University, Ago-Iwoye, Ogun State, Nigeria. IOSR Journal of Humanities and Social Science (IOSR-JHSS) Volume 20, Issue 5, Ver. IV (May. 2015), PP 16-26 e-ISSN: 2279-0837, p-ISSN: 2279-0845.www.iosrjournals.org.

ii. Akangbe, J.A., (2013).'An Appraisal of Transportation Facilities Effects on Agricultural Development in Moro Local Government Area, Kwara State, Nigeria in Ethiopian Journal of Environmental Studies and Management vol.6 no.2,2013.

iii. AmanArora \& Manish Kumar Pandey (2011).Transportation Network Model and Network Analysis of road Networks. Geographical Analyst, Lepton Software Export \& Research Private Limited, Gurgaon, Senior Research Fellow, Banaras Hindu University, Varanasi, U.P., India. 12th Esri India User Conference 2011.

iv. Babalola O. J. \& Oladosu J.O., (2018). Effect of Transport Facilities on Farm Crops Wastage in Oyo State, Nigeria. International Journal of Advanced Research in Science, Engineering and Technology. Vol. 5, issue 10, October 2018. ISSN: 2350-0328.www.ijarset.com.

v. Cesar Ducruet \& Igor Lugo (2009). Structure and Dynamics of Transportation networks: Models and Applications.

vi. Cliff, A. P. Haggett, and K. Ord. (1979).Applications of Graph Theory, Graph Theory and Geography, pages 293-326. Academic Press, London, r. Wilson and l. Beinecke (eds) edition.

vii. Grace O. K., Olusanya E. O., \& Mees A. S., (2013). Spatio -Temporal Analysis of Characteristics and Causes of Road Traffic Crashes in Oyo State of Nigeria. Department of Statistics and Economics, University of Ibadan and Department of Mathematics \& Statistics, Federal Polytechnic, Offa, Nigeria. The Nigerian Health Journal, Vol. 13, No 4, October- December, 2013.

viii. Jean - Paul Rodrigue (2020). The geography of transport system. Fifth edition, ISBN: 978-0-367-36463-2, New York. https://transportgeography.org/?page_id $=6971$.

ix. Kansky, K., (1963). Structure of Transportation Networks: Relationships Between Network Geometry and Regional Characteristics. Chicago: University of Chicago, Department of Geography. Research Paper No. 84.

x. Murchalnd, J.D. (1969). Road Traffic Distribution in Equilibrium. Conference paper, Mathematical Methods in the Economic Science, Mathematics forshungs institute, Obserwolfack, West Germany.

xi. Njike CHIGBU \& Susan Chiawolam NMEREGINI (2017). Use of GIS in the Study of the Impact of Road Network Accessibility in Electricity Infrastructure Distribution and Monitoring-A Review. FIG Working Week 2017 Surveying the world of tomorrow - From digitalization to augmented reality Helsinki, Finland, May 29-June 2, 2017.

xii. Owen Richard Owen (1988). The Trunk A Network in Nigeria: The Issues of Connectivity and Accessibility. A dissertation submitted in partial fulfillment of the requirements for the degree of Doctor of Philosophy in Urban Studies. Portland State University.1130.10.15760/etd.1129.

xiii. Rabirou K. Adeolu and Stella, (2012). Effect of Rural Transportation System on Agricultural Productivity in Oyo State, Nigeria'. Journal of Agriculture and Rural Development in Tropics and Subtropics vol. 113 no1 (2012)13-19. 
xiv. 9788131605561

xv. Transportation Planning. Singapore: pp 63-76.

xvi. Tanuja Shanmukhappa, Ivan Wang-HeiHo \& ChiKong Tse (2018).Spatial Analysis of Bus Transport Networks uses Network Theory. Article in Physical A: Statistical Mechanics and its Applications • February 2018. DOI: 10.1016/j.physa.2018.02.111. https://www.researchgate.net/publication/323435043.

xvii. Watts \& Witham, (2012). Social network analysis of sustainable transportation organization. UVM Transportation Research Center. 